\title{
Effect Of Gender Difference On Visual Reaction Time : A Study On Medical Students Of Bhavnagar Region
}

\author{
Dr. Ritesh M. Karia ${ }^{1}$,Dr. Tejas P. Ghuntla ${ }^{2}$, Dr. Hemant B. Mehta ${ }^{3}$, \\ Dr. Pradnya A. Gokhale ${ }^{4}$, Dr. Chinmay J. Shah ${ }^{5}$ \\ ${ }^{1}$ Assistant Professor, Department of Physiology, GMERS Medical College \& Hospital, Dharpur-Patan, Gujarat, \\ India, ${ }^{2}$ Assistant Professor, Department of Physiology, Govt. Medical College, Bhavnagar, Gujarat, India \\ ${ }^{3}$ Prof \& Head, Department of Physiology, Govt. Medical College, Bhavnagar, Gujarat, India \\ ${ }^{4}$ Additional Professor, Department of Physiology, Govt. Medical College, Bhavnagar, Gujarat, India \\ ${ }^{5}$ Associate Professor, Department of Physiology, Govt. Medical College, Bhavnagar, Gujarat, India
}

\begin{abstract}
:
The measurement of visual reaction time has been used to evaluate the processing speed of Central Nervous System and the co-ordination between the sensory and motor systems. Reaction time is influenced by different factors. Effect of gender difference on visual reaction time has been observed in this study. Present study was carried out on 100 medical students of Bhavnagar medical college between the age of 17-20. Out of them 50 were boys and 50 were girls. Study was done under three module. In first module detail medical history of subject were taken, in second module visual reaction time of subjects was measured using reaction time instrument and in third module statical analysis was done by unpaired ' $t$ ' test. From study it was concluded that reaction time is less in boys than girls.
\end{abstract}

$\underline{\text { Keywords: gender difference, medical students, visual reaction time }}$

\section{INTRODUCTION}

Human body responses to a number of external environmental stimuli of different modalities. Human body gives a desired \& purposeful voluntary response to different types of stimuli. Reaction is a purposeful voluntary response to stimulus. There is certain time period between application of stimulus and appropriate motor response. Reaction time is defined as interval of time between presentation of stimulus and appearance of appropriate voluntary response in subject. Reaction time has physiological significance and is a simple and non - invasive test for peripheral as well as central neural structures ${ }^{1}$. Reaction time measurement is an indirect index of processing capability of central nervous system. Reaction time measurement helps in determining sensory motor association and performance of an individual. ${ }^{2}$ It determines the alertness of a person because how quickly a person responds to a stimulus depends on his reaction time. Various factors influencing human reaction time are age, sex, left or right hand, central versus peripheral vision, practice, fatigue, fasting, breathing cycle, personality types, exercise, and intelligence of the subject. Out of these various factors, in this study we had studied the time taken between application of visual stimulus and response obtained and comparison of the response in boys and girls volunteer. ${ }^{3}$

\section{Material and Method :}

The present study was carried out at Department of Physiology, Govt. Medical College, Bhavnagar, Gujarat, India in 100 medical students. Out of them 50 were boys and 50 were girls.). The study was done under three module.

\subsection{Subject Preparation :}

This included a detail medical history of subjects which included history of present illness, past history ( hypertension, diabetes, tuberculosis, psychiatric disorders, E.N.T. diseases, ophthalmic disease, head injury, epilepsy, drug therapy etc. ), personal history ( diet, sleep pattern, exercise \& sports habits, vehicle driving, addiction ). The medical history was taken to rule out any medical or surgical disease which would affect reaction time of individual. The experimental protocol was explained to all the subjects and written consent was obtained from them. Subject was explained and demonstrated about the procedure to be performed.

\subsection{Measurement Of Visual Reaction Time :}

This was recorded with the multiple choice apparatus $653 \mathrm{MP}$ (reaction time apparatus), an Inco company product (Ambala) has resolution of 0.001 seconds. The visual stimuli are red, green yellow and orange lights The subjects sits to one side and examiner sits to other side of instrument. When examiner press switch visual stimuli appear on screen which is in front of the subjects. The instrument automatically starts counting of time. When subject press the key as a response to visual stimuli instrument stops counting of time. This time is taken as reaction time. During the reaction time testing, visual stimuli was given for three times and minimum reaction time was taken as the final reaction time for that sensory modality of that subject. 
The visual reaction times were measured under two categories:

1. Simple Reaction Time.

2. Choice Reaction Time.

In the simple reaction time task subjects were tested for their visual reaction time by just reacting to the visual stimuli. This was simple reaction time task. In the choice reaction time task the person had react to four different colour of light i.e. red, green, yellow or orange by pressing the respective key for the colour as soon as that respective colour is presented on the screen which may be red, green, yellow or orange

\subsection{Statical Analysis :}

The part consisted of the statistical analysis of the reaction time measurements. The reaction time were taken as mean+standard deviation. The level of significance between boys and girls was tested by the unpaired t-test. The observation was taken as significant if $\mathrm{P}$-value $<0.05$

\section{Results :}

\begin{tabular}{|l|l|l|}
\hline $\begin{array}{l}\text { Simple Visual Reaction time } \\
\text { (Boys ) }\end{array}$ & $\begin{array}{c}\text { Simple Visual Reaction time } \\
\text { ( Girls ) }\end{array}$ & P- Value \\
\hline $0.13990 \pm 0.02637$ & $0.15990 \pm 0.02637$ & Significant \\
\hline
\end{tabular}

Table 1 shows measured value of simple visual reaction time (mean \pm SD) in boys and girls.

\begin{tabular}{|l|l|l|}
\hline $\begin{array}{l}\text { Choice Visual Reaction time } \\
\text { (Boys ) }\end{array}$ & $\begin{array}{l}\text { Choice Visual Reaction time } \\
\text { ( Girls ) }\end{array}$ & P- Value \\
\hline $0.26858 \pm 0.06664$ & $0.30268 \pm 0.07471$ & Significant \\
\hline
\end{tabular}

Table 2 shows measured value of choice visual reaction time $($ mean \pm SD) in boys and girls

\section{DISCUSSION:}

From the table $-1 \& 2$ it is clear that mean value of simple and choice visual reaction time in boys is $0.13990 \pm 0.02637$ and $0.26858 \pm 0.06664$ respectively, while that of girls is $0.15990 \pm 0.02637$ and $0.30268 \pm 0.07471$ respectively, which is statically significant $(\mathrm{p}<0.05)$ so boys has lesser visual reaction time than that of girls. Our observation are consistent with the observations of the other workers who observed that females had a longer reaction time when compared to males. ${ }^{4,5}$

Bruce and Russel (1962) explained it on the basis of varying level of sex steroids during different phases of menstrual cycle which have sodium and water retaining effect. This retention of salt and water could modify the axonal conduction. It is also suggested to alter the availability of the neurotransmitter at the synaptic level. This modulation of neurotransmitter coupled with altered rate of impulse transmission due to fluctuation in the levels of hormones affect the sensory motor association with the processing speed at the Central Nervous System ${ }^{6,7}$

\section{CONCLUSION:}

From the study it is clear that boys has lesser reaction time than girls. So we can say human visual reaction time is less in males than their female counter part.

\section{ACKNOWLEDGMENT:}

We wish to thank to our Dean who allowed us to carry out this study in the institute. 


\section{REFERENCES:}

1. M Mohan, DP Thombre, AK Das, N Subramanian, S Chandrasekar. Reaction time in clinical diabetes Mellitus. Ind J Physiol Pharmacol 1984; 28: 311-314.

2. S Das, A Gandhi, S Modal. Effect of pre-menstrual stress on audiovisual reaction time \& audiogram. Ind J Physiol Pharmacol 1997; 41: 67-70.

3. S Bamne, A. Fadia, A. Jadhav Effect of colour and gender on human reaction time. Ind J Physiol Pharmacol 2011; $55(4): 388-389$

4. JD Pathak, YB Dixit, MS Rao. Normal visual reaction time: Effect of missing a meal on it. J Indian M A 1962; 38 : 530-532.

5. D Venkatesh, DL Ramachandra, BN Suresh, BK Rajan. Impact of psychological stress, gender and colour on visual response latency. Ind. J.Physiol.Pharmac 2002; 46: 333-337

6. J Bruce, GFM Russell. Premenstrual tension: a study of weight changes and balances of Na+, water and potassium. Lancet 1962; 11: 267-271

7. Namita, D. Rajan, D. Shenvi A comparative study of auditory and visual reaction time in males and females staff during shift duty in the hospital. Biomedical research 2010; 21(2) : 199-203 